\author{
NARRAR LO INUSUAL: BESTIARIA VIDA \\ DE CECILIA EUDAVE Y EL ANIMAL SOBRE \\ LA PIEDRA DE DANIELA TARAZONA
}

\author{
Carmen Alemany Bay
}

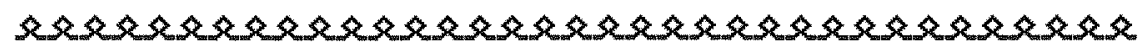

$E_{\mathrm{N}}$ el año 2008 la escritora mexicana Cecilia Eudave (1968) publica su primera novela, Bestiaria vida (2008), Premio Nacional de Novela Corta Juan García Ponce. Le precedían los libros de relatos Técnicamente humanos (1996), Invenciones enfermas (1997), Registro de imposibles (2000), Países inexistentes (2004) y Sirenas de mercurio (2007). ${ }^{1}$ En esta misma fecha, también la autora mexicana Daniela Tarazona (1975) saca a la luz su primera obra, la novela titulada $E$ l animal sobre la piedra. ${ }^{2}$ Notables son las relaciones entre ambas ficciones a nivel textual pero también confluyen una serie de elementos que hacen más visibles estas semblanzas y a ellas acudiremos.

Ambas autoras, y a pesar de que la crítica en ocasiones las ha ubicado en diferentes generaciones, ${ }^{3}$ forman parte de un mismo contexto sociocultural y comparten semejantes preocupaciones estéticas que contribuyen a una escritura en la que se han perpetuado mecanismos como la fragmentariedad, la intertextualidad, la reescritura y la reinterpretación de textos canónicos o la metaficción. Como ha señalado Luz Elena Zamudio con respecto a las narradoras mexicanas del siglo XXI, y a ello nos referiremos en líneas ulteriores, muchas de ellas "eligen tropos que definen su manera de narrar (se destaca la sinestesia, la

\footnotetext{
1 A estas publicaciones se suman tres ficciones calificadas como literatura juvenil y protagonizadas por la Dra. Dench; Aislados (2015) es su novela juvenil más reciente. Se suman la colección de microrrelatos Para viajeros improbables (2011) y el cuento infantil Papá Oso (2010); así como En primera persona (2014), una selección de relatos publicada en España.

${ }^{2}$ Hasta la fecha, la autora ha publicado otra novela, El beso de la liebre (2012), que se enmarcaría de forma genérica en la ciencia ficción.

${ }^{3}$ Castro Ricalde, entre tantos otros críticos, utiliza el adjetivo "novísimas" para referirse a autoras nacidas a partir de los 70; otros en cambio se decantan por situar la barrera a partir de las nacidas en 1968. Desde nuestro punto de vista habría que tener una amplitud temporal más laxa porque creemos que gran parte de las narradoras que comenzaron a publicar a finales del siglo XX comparten las mismas inquietudes que las de los últimos años.
} 
sinécdoque y la metonimia) [ . . . El juego entre las dualidades: verdad-mentira, realidad-ficción y fantasía-realidad son marcas que distinguen el corpus" (5).

En estas novelas, en concreto, las autoras ingresan de una manera menos ortodoxa que las anteriores en el universo femenino: inspeccionan otras vías para hablar de la mujer, de su identidad, en un afán intimista y de búsqueda. Se trata de una exploración de la existencia humana desde su ámbito profundo con el fin de penetrar en las esferas más introspectivas de los personajes, dejándolos completamente descubiertos ante el lector. Ellas, y no pocas de las últimas narradoras mexicanas de hoy, hablan de las mujeres desde una perspectiva de identidad más actualizada y adaptada a la propia evolución de los roles de género.

En Bestiaria vida y en El animal sobre la piedra, Eudave y Tarazona respectivamente cuentan sus historias desde la peculiar perspectiva de lo que a voz de pronto - en ocasiones desde la crítica somos excesivamente genéricos podría calificarse como fantástico. Sin embargo, no se pliegan a los dictados de este género, y su discurso tiene características peculiares, que intentaremos explicar, y que denominamos "narrativa de lo inusual." Totalmente emancipadas del realismo mágico acuden a otras esferas de lo real para transcenderlo pero sin volcarse en lo fantástico.

El intimismo y la poeticidad del lenguaje, tan notable en sus novelas, como esa manera peculiar de acceder a otras vías de la realidad proceden, creemos, de narradoras mexicanas del medio siglo como Amparo Dávila o Guadalupe Dueñas - más la primera que la segunda -, a cierta distancia estarían Inés Arredondo o Elena Garro. Creemos que Tiempo destrozado de Amparo Dávila, y básicamente los relatos "La celda," "La señorita Julia" o "El espejo," bien podrían ser referentes de esta "narrativa de lo inusual" que se nutre asimismo de Juan José Arreola. Otros modelos imprescindibles, fuera de las fronteras nacionales, son desde luego Frank Kafka y Jorge Luis Borges, amén de Clarice Lispector en el caso de Tarazona. ${ }^{4}$

Son cuantiosos los denominadores comunes que unen ambos textos más allá de la coincidencia en la fecha de publicación. ${ }^{5}$ Sin duda es interesante

${ }^{4}$ Por no prolongar la justificación de estas afinidades, diré que El animal sobre la piedra aparece encabezada por una cita de Clarise Lispector; Daniela Tarazona es autora de un ensayo sobre la escritora brasileña, y en no pocas ocasiones ha declarado su admiración por Amparo Dávila y por Borges. La influencia de Kafka es más que evidente en la novela; y éste es uno de los autores predilectos de Eudave. Otros de los referentes eudavianos son Borges, Arreola y Dávila; y es autora del siguiente artículo: "Lo innombrable y lo monstruoso femenino en Tiempo destrozado de Amparo Dávila" en Sobre lo fantástico mexicano.

${ }^{5}$ Cándida Elizabeth Vivero Marín hizo coincidir ambas en un estudio, pero sus reflexiones se circunscriben a "la reconstrucción del imaginario familiar, por medio de la infancia, desde una perspectiva de género" (82). 
que la propia Daniela Tarazona, en el artículo "Los cuerpos insólitos en tres novelas de escritoras mexicanas contemporáneas," reflexione sobre Bestiaria vida junto a El camino de Santiago (2003) de Patricia Laurent Kullick y Odio (2012) de Adriana Díaz Enciso. En él reconoce la sintonía con las obras citadas debido a que indagan "en temas que también están presentes en mis libros y por el deseo de abordar en estas páginas la creación de universos femeninos fascinantes que suelen pasar desapercibidos" (179); en líneas sucesivas especificaba que la lectura de Bestiaria vida fue más bien tardía respecto a su fecha de publicación (180).

Para comprender en toda su dimensión estas y otras afinidades, resumiremos sucintamente el asunto de ambas tramas y algunos otros pormenores con el fin de relacionarlas. Conviene apuntar de entrada que en las dos novelas se ha elegido la primera persona del singular, lo que Gérard Genette denomina "autobiografía ficticia;" son obras que abordan, cada una a su manera, aspectos de la condición humana así como el autodescubrimiento, la búsqueda de la identidad desde la voz de una mujer.

En Bestiaria vida la protagonista se enfrenta a sus propios demonios personales y en cierto momento, al final de la novela, hace un ejercicio de reflexión para contarnos su historia, desde su nacimiento - al nacer sus familiares la identifican con un caracol: "naciste enrollada como un caracol" (9). A pesar del paso del tiempo: "estoy como cuando nací, supongo, sintiendo ese frío inmenso colarse por entre mis huesos, obligándome a enrollarme como un caracol" (10) -. Su objetivo no es otro que analizar por qué ha llegado a la situación en la que se encuentra. Su vida, sus relaciones familiares, amorosas y de amistad, los vínculos entre el sujeto y su entorno familiar se explican a través de personajes que mediante analogías son identificados con el bestiario literario, y su existencia se enmarca en un espacio mítico como lo es el laberinto. Estos personajes aparecen en el capítulo segundo en el que la autora se sirve de epígrafes para presentárnoslos: "La Basilisco" es identificada con la madre, "El Licántropo" con el padre, "El cancerbero y un búfalo extraño" responden al abuelo y al tío respectivamente, y "La innombrable," es la tía de la que nadie quiere hablar; en un capítulo anterior saca colación a "la Súcubo," la hermana. Sin embargo, los personajes del bestiario son fagotizados por la autora con el fin de familiarizarlos y adaptarlos, reactualizarlos al contexto de Bestiaria vida para humanizar de este modo el bestiario. Lo importante aquí es que la protagonista no ve a estos personajes como a las citadas bestias sino que establece una analogía, detalle de importancia para establecer líneas diferenciales entre lo fantástico y lo inusual. 
Cecilia Eudave, reiteramos, parte en cierta medida de El libro de los seres imaginarios de Jorge Luis Borges para adaptar las características que estos personajes simbolizan para, mediante analogías, crear finalmente una alegoría de la vida muy personal que nos muestra ese yo en tránsito que es la protagonista; de ahí también la explicación del título de la novela, Bestiaria vida.

El animal sobre la piedra es un diario que relata la metamorfosis del cuerpo de una mujer quien escrupulosamente detalla su transformación en un reptil. Tras la muerte de la madre, Irma decide realizar un viaje al mar. Tras un incidente en el tren, acaba en la casa de un desconocido que se convierte en su compañero y quien convive con una mascota un tanto inusual, un oso hormiguero llamado Lisandro. Es a lo largo de esa estancia cuando su cuerpo comienza a padecer progresivamente una extraña transformación, una metamorfosis que se sugiere desde el tercer capítulo "Sueño con la selva" (25). La pérdida, el azar y el destino son los vértices por los que se articula esta crónica; pero también la huida, huir de la casa y huir de sí misma: "No quiero estar en mi cuerpo" (13); fruto de esa necesidad de escapar proviene su metamorfosis en reptil.

Desde un punto de vista formal, estamos ante dos novelas breves, ${ }^{6}$ brevedad que contribuye sin duda a articular lo narrativo y que en este caso va acompañado de un fragmentarismo evidente tan propio de las ficciones posmodernas proclives al hibridismo de tipo genérico que es alentado por las digresiones, las indagaciones o los saltos espacio-temporales. El fragmentarismo en los presentes textos procede fundamentalmente de la estructuración del relato: breves capítulos que intentan organizar una materia en ocasiones compleja.

En cuanto a la temporalidad, en ambas novelas oscilan entre el presente y el tiempo pasado, tiempo este último que resulta fundamental para entender el hoy en el que viven las protagonistas. El tiempo se asume altamente subjetivo, pero además la sensación es que los personajes lo sienten como un "tiempo roto," un tiempo que por las experiencias vividas se quebró.

Creemos que en la narrativa mexicana de las últimas décadas existen una serie de textos escritos por mujeres en los que con un renovado registro y con la frescura del atrevimiento plantean otras formas de penetración en la realidad, y en su caso una nueva manera de acceder a lo femenino. Hablamos de una literatura que nos plantea una ecuación asentada de nuevo sobre la base

${ }^{6}$ Habría que aclarar en este punto que en la primera edición de El animal sobre la piedra, publicada en la editorial mexicana Almadía, la novela tenía una extensión de 170 páginas que se redujeron a 106 cuando en 2011 se publicó en la editorial argentina Entropía. Se trata de la misma novela aunque notablemente ampliada con efectos editoriales - múltiples espacios y páginas en blanco - en su primera edición. 
de la escritura elíptica y enigmática pero con una inédita combinación de los términos: lo insólito ${ }^{7}$ con el realismo cotidiano salpicados en ocasiones por el humor (en el caso de Bestiaria vida), en situaciones que se instalan en un curioso vaivén entre lo racional y lo irracional pero dentro del amplio espectro de lo real. No se posicionan ni en lo maravilloso, ni el realismo mágico y ni en la ciencia ficción, aunque en ocasiones en su discurso puedan hacer puntualmente uso de estos géneros narrativos. La etiqueta de "narrativa de lo inusual" nos permite amparar una literatura que se mueve en baremos no usuales, infrecuentes; pues no hay en sus discursos una intencionalidad explícitamente fantástica aunque sí la necesidad de acudir a otros parámetros que fluctúan en la franja que oscila entre lo real y lo insólito, como anotábamos en líneas ulteriores, pero que termina por detenerse en lo primero. Una forma de ficción en la que prima la incertidumbre aunque los hechos transcurran en el plano real con transiciones hacia lo onírico o lo delirante; y en ese trance el autor abandona al leyente en su perplejidad, pues esta ambigüedad tiende a provocar la vacilación interpretativa del lector. Sus discursos se nutren de tropos que proceden fundamentalmente de lo poético - analogías, metáforas, comparaciones, alegorías - que les sirven para explicitar de otro modo lo real, una realidad que finalmente vuelve con todo su peso.

Este tipo discurso, que podríamos calificar como una evolución, o acaso una variante del neofantástico como argumentaremos más tarde, es un producto de la posmodernidad en el sentido de que se apropian de otros géneros discursivos - hay una voluntad de atravesar géneros una y otra vez y no quedarse fijo en uno. Se ejerce la hibridez discursiva en la que la representación metafórica es solo una necesidad de representación de la realidad que no bus-ca desestabilizarla, y además los personajes son conscientes de estar en ella con leves tránsitos a otras realidades; universos complejos, ambiguos, ante una realidad trastocada por la imaginación o por la desestabilización de quien lo enuncia y que está haciendo una reinterpretación de la realidad a partir de esos parámetros. De ahí que sea común encontrarse con elucubraciones o desdoblamientos para hallar una explicación de la realidad: me desprendo de mí para comprenderme. Se trata de mundos inusuales que son sistemas de representación metafórica y que intentan revelar las emociones ocultas detrás de las circunstancias cotidianas. En cualquier caso, no se trata de textos que "ambientados en un mundo cotidiano semejante al del lector, presentan fenómenos, situaciones imposibles que plantean una trasgresión de lo real [. . .]

${ }^{7}$ El término "insólito" empezó a ser utilizado por investigadores portugueses y brasileños, uno de los primeros fue Filipe Furtado. El término engloba tanto lo maravilloso, como lo fantástico, el realismo mágico y la ciencia ficción. 
que deja de ser familiar y se convierte en algo incomprensible y, como tal, amenazador" (Roas y Casas 11-12), tal como se ha definido lo fantástico.

Para argumentar nuestra teoría daremos cuenta de lo que la crítica ha dicho al enfrentarse a las dos novelas objeto de nuestro análisis. En el artículo introductorio a Estrategias y figuraciones de lo insólito en la narrativa mexicana (siglos XIX-XXI), José Carlos González Boixo apunta que Daniela Tarazona se ocupa en el volumen de tres novelas de autoras mexicanas nacidas en los años sesenta "cuya temática tiene una sorprendente unidad y que pueden enmarcarse en la categoría de lo insólito o de lo fantástico, entendido en un sentido laxo del término" (6). Añade más adelante que "Lo que en principio podría parecer una historia habitual en la literatura fantástica y, en especial, de la ciencia ficción, se convierte en vehículo simbólico para indagar en el universo femenino y en el reconocimiento de su identidad [. . . Son historias en las que los límites de lo real y de lo imaginado se difuminan" (6). El propio González Boixo vislumbra en líneas posteriores que El huésped de Guadalupe Nettel y El animal sobre la piedra de Tarazona podrían formar parte de este tipo de narrativa (7), y creemos que efectivamente así es, como también lo son otras autoras y títulos como Paulette Jonguitud Acosta con Moho (2010), Lourdes Meraz con Los abismos de la piel (2013), así como algunas obras de Ana María García Bergua, algunos relatos de Guadalupe Nettel y unos cuantos cuentos de la propia Cecilia Eudave. Estas novelas, también con diferencias entre ellas, conformarían una nueva manera de narrar desde lo inusual, pues el término insólito resulta excesivamente abarcador y se incluyen en un mismo paradigma obras excesivamente disímiles. Debemos aclarar en este punto que la narrativa inusual no se limita a un determinado país ni a una cuestión de género. Solo que a estas alturas únicamente abordamos esta parcela en vistas a investigaciones futuras que nos permitan ver el alcance de esta vía de expresión generada en el nuevo milenio.

González Boixo habla de lo fantástico en un sentido laxo, señalando, como hemos dicho, que "son historias en las que los límites de lo real y de lo imaginado se difuminan." Sin embargo, y en el caso de Eudave, su obra ha estado marcada por ser una de las representantes del neofantástico mexicano, pues así fue clasificada por Ana Rosa Domenella en el artículo "Tres cuentistas neofantásticas" (1999). Solo que si bien sus primeras publicaciones podrían ser clasificadas de neofantásticas, a partir de Registro de imposibles sus temas se articulan en lo que hemos denominado "narrativa de lo inusual," lo cual no es óbice para que en otras publicaciones traslade su discurso hacia códigos propiamente fantásticos, como en "El oculista" o "Con la boca en la mano." Siguiendo esa inercia, la mayoría de las reseñas que se 
han publicado sobre Bestiaria vida aluden al carácter fantástico o neofantástico de la obra.

Si en Bestiaria vida y en El animal sobre la piedra sus autoras utilizan analogías y otros tropos para reflejar la realidad de sus personajes, independientemente de que esas a su vez representen otras metaforizaciones de carácter abstracto, alegorías (la condición humana así como del autodescubrimiento, la búsqueda de la identidad desde la voz de una mujer, la maternidad, etc.), lo decisivo es que en estos casos no hay una incursión del elemento insólito en la vida cotidiana como apertura, como pasaje hacia nuevas realidades en las que lo cotidiano toma otro rumbo; los personajes tienen dudas, incertidumbres, vacilaciones, pero acaban afincándose en la realidad. Y en lo que concierne al lector, en algunos momentos, y por tratarse de textos muy ambiguos, pueden dudar de la naturaleza de esa realidad; pero insistimos, al final ésta cae por su peso. Si lo neofantástico surgía como una corriente literaria posterior a lo fantástico que promulgaba la aceptación de una verosimilitud nueva, creemos que en estos tiempos de una posmodernidad asentada se han creado nuevas formas de acceder a lo real sin renunciar a ciertas vacilaciones; y tomando las palabras de Jaime Alazraki podríamos estar ante "una nueva postulación de la realidad, de una nueva percepción del mundo, que modifica la organización del relato, su funcionamiento, y cuyos propósitos difieren considerablemente de los perseguidos." Al pensar esta nueva realidad, Alazraki tomaba en cuenta, "por lo fantástico" (28) y nosotros, en cambio, "lo neofantástico."

Aleccionadoras para nuestra argumentación nos parecen las palabras con las que Juan Tomás Martínez Gutiérrez se refiere a Bestiaria vida, pues desde nuestro punto de vista acierta en la intencionalidad que la autora tuvo al escribir la obra y también lo que llamamos "narrativa de lo inusual": "es necesario tener en cuenta que la narración se presenta codificada como una novela realista. Los monstruos no existen en un sentido literal [. . . la revelación de la identidad monstruosa, esto es, se propone una figura mitológica, animal o monstruo como su representación" $(132,134)$. Más adelante Martínez Gutiérrez afirma que "Bestiaria vida se articula alrededor de problemáticas que poco tienen que ver con el tema de lo fantástico: si bien algunos personajes son bestias o monstruos, lo son sólo en función de la necesidad de la narradora por caracterizarlos así; existe una voluntad de enmascaramiento de la realidad que pasa por nombrar" (143). Y tiene razón. Como acertadamente señaló Daniela Tarazona sobre Bestiaria vida, "Los cuerpos representados en la novela son denominados como sobrenaturales: Súcubo, Basilisco, Licántropo, etc. Eudave toma la simbología de estas creaturas para definir las cualidades de sus personajes" (187). Respecto a si se trata de un texto fantás- 
tico, Martínez Gutiérrez lo resuelve de la siguiente manera: "Las pocas situaciones que recrean una vacilación o que cuestionan los límites de la realidad, se resuelven al optar por el sueño" (138). Sin descartar que haya momentos, añadimos nosotros, en lo que lo fantástico aflora puntualmente. Ponemos como ejemplos la historia de un antepasado de la protagonista, que decían que era mitad blanco y mitad negro; o el relato, tan propio de lo fantástico, pero que aquí es puesto en cuestión, como lo es el de la mujer que queda atrapada en el espejo con su doble: "la parienta cercana de la abuela que se perdió entre los espejos es una metáfora de lo que pasó; se volvió loca, o en verdad esto puede pasar en el sentido más literal: cualquiera puede perderse en un reflejo" (79). En ocasiones se incursiona en la ciencia ficción, como en el capítulo "Los invasores del espacio interior."

Sugerente nos parece, respecto a los temas que estamos argumentando, la respuesta que en una entrevista pública realicé a Cecilia Eudave el 12 de noviembre de 2014 en la Universidad de Alicante, y en la que le planteé que parte de su obra podría definirse bajo el término de "narrativa de lo inusual." Estas fueron sus palabras:

Si bien algunos de mis textos son insólitos, pues el peso de la irrealidad gana en el contexto de la historia, en la nueva etapa de mi narrativa, así como en Bestiaria vida y algunos relatos anteriores, tu término de lo inusual cobijaría esa forma mía de representar de una manera diferente la realidad que me aqueja entendiendo yo que no es fantástica sino una forma distinta, otra forma de leer la realidad a través de analogías, metáforas y otros mecanismos que, insisto, me sirven para representar la realidad.

En lo que concierne a la obra de Daniela Tarazona, en una entrevista realizada por Valeria Tentoni, la novelista habla en los siguientes términos de su novela, palabras que nos pueden servir para encarar cuáles serían las características de las narraciones inusuales: "Yo quería escribir una historia sobre todo que fuera ambigua, donde estuviera jugándose todo el tiempo la posibilidad de que el lector juzgara si realmente estaba pasando que ella se transformase en este animal o no. Parece a veces que sí, pero no del todo. Quería hacer ese juego de doble vista, de movimiento."

Es interesante, para seguir en la fijación del término de lo inusual, escuchar las voces de la crítica para ir demarcando nuestra postura. Claudia Amengual, en el suplemento Hoja por hoja, escribe que El animal sobre la piedra "es una recreación alegórica del doloroso proceso de crecer, una invitación a reflexionar." Por su parte, Irad Nieto anotaba una observación que bien podría servirnos para ambas novelas desde nuestra perspectiva de lectura, pues se trata de "una metáfora de la supervivencia ante una realidad, tanto interior como exterior, que nos embiste." Además, afirma más adelante que 
la historia de El animal sobre la piedra "no concede al lector ninguna certeza para saber si los hechos (si es que lo son) transcurren en un plano real, onírico o delirante; por el contrario, lo abandona en su perplejidad y lo deja vagando entre símbolos como la muerte, la maternidad, el útero $\mathrm{y}$, por supuesto, lo humano-animal." El final de la novela es revelador en este sentido, ya que la protagonista se encuentra con el huevo roto que es la metáfora de una maternidad truncada.

También Jorge Volpi afirma que Tarazona escribe "un texto que puede ser leído no sólo como el relato realista de una mujer perturbada por la doble tensión de la maternidad y la muerte, sino como una novela fantástica" (132). La duda, entre lo real y lo fantástico, se aclara en la contraportada de la edición publicada por la editorial Entropía en la que se afirma que "Daniela Tarazona ha logrado abordar el tema desprendiéndose del lastre de la literatura fantástica y el simbolismo didáctico. El animal sobre la piedra es una novela profundamente biológica e introspectiva antes que una fábula o una digresión acerca de lo sobrenatural." Afinando un poco más en la novela, Alejandro Ramírez Lambarry dedica en su Tesis doctoral un capítulo a El animal sobre la piedra. Ahí hace referencia a lo fantástico en ella, estableciendo una curiosa diferencia entre lo que Ramírez Lambarry denomina como los testigos (el compañero y Lisandro) y la voz de la narradora: "los personajes que hemos denominado Testigos aportan el carácter fantástico a la novela [. . . ] Si los Testigos contribuyen con su actuar a propagar la incertidumbre, la narradora lo hace con la diversidad de realidades posibles" (255-256).

Creemos que en buena lid la novela encara la pérdida de la percepción de la realidad por parte de la protagonista quien cree pertenecer, como su madre y su hermana, a la estirpe de los reptiles, aunque ellas no quisieron dar el paso para reconocerse como tales: "Mi madre y mi hermana no supieron sobrevivir con nuestras cualidades únicas" (144). Por eso, estando en el hospital, desova un huevo tal como leemos en las palabras que dan el cierre a la novela: "Bajo mi cama encontré el huevo [. . .] Cuando lo tomé entre las manos descubrí que estaba vacío" (170).

Esta interpretación de su realidad, que se dicta desde la primera persona, no lo olvidemos, ni tampoco que contar desde esta perspectiva dificulta al lector si lo que se cuenta es real o no, no es más que un quiebre psicológico fruto de su mente enajenada. Por eso, lo relatado, su conversión en reptil, nace de la enajenación que es sostenida a lo largo de la novela por su compañero. Lo dicho en ella, lo vivido en esta ficción, es la crónica de una mente delirante; no se relata un hecho fantástico como sí lo es La metamorfosis de Frank Kafka, sino un hecho real, desarrollado en espacios reales. La narra- 
ción proviene de quien, desde un proceso esquizoide, cree estar viviendo esa experiencia. Y toda la novela está construida para sostener la ambigüedad que creemos se resuelve en el último capítulo titulado "Fábula." Lo contado es una fábula posmoderna que relata el resultado de una transformación personal, una metáfora del universo femenino, de esos "universos femeninos fascinantes que suelen pasar desapercibidos" de los que hablara Tarazona en su artículo a propósito de otras narradoras: la maternidad como una metáfora deviene alegoría, los sucesivos abandonos - el de la madre y la hermana, también el del compañero que finalmente la deja -, la necesidad de la mudanza. "La animalización de Irma," como apuntara Maricruz Castro Ricalde, "dirige la mirada sobre los procesos biológicos y materiales y pone en crisis la noción de sujeto al condensar en sí misma al yo y al otro" (72).

Bestiaria vida y El animal sobre la piedra se acogen a nuevos códigos, a nuevas expresiones propias de la posmodernidad. Eudave y Tarazona se han servido de sistemas metafóricos, analógicos, ambiguos, para narrar desde lo inusual, para contar realidades inusuales, pues la realidad de sus personajes es tan cruda que se inventan otra, creando realidades paralelas que irremisiblemente se enfrentan con la misma realidad. Estas nuevas formas de narrar expresan, en este caso, la profunda insatisfacción del yo femenino con el mundo real.

\title{
UNIVERSIDAD DE ALICANTE
}

\author{
OBRAS CTTADAS
}

Alazraki, Jaime. En busca del unicornio: Los cuentos de Julio Cortázar. Elementos para una poética de lo neofantástico. Madrid: Gredos, 1983.

Amengual, Claudia. "El animal sobre la piedra. Daniela Tarazona." Hoja por hoja. Suplemento de libros. 139 (2008). Web. 5 octubre 2015.

Castro Ricalde, Maricruz. "Cuerpo y violencia. Novísimas novelistas mexicanas: Daniela Tarazona y Bibiana Camacho." Les Ateliers du SAL 3 (2013): 66-79.

Eudave, Cecilia. Bestiaria vida. México: Ficticia, 2008.

Sobre lo fantástico mexicano. Orlando: Letra Roja, 2008.

González Boixo, José Carlos. "Hacia una definición de 'lo insólito' en la narrativa mexicana contemporánea: Una introducción." Estrategias y figuraciones de lo insólito en la narrativa mexicana (siglos XIX-XXXI). Ed. Javier Ordiz. Bern: Peter Lang, 2014. 1-8.

Ramírez Lambarry, Alejandro. "La voz animal en la literatura hispanoamericana de la segunda mitad del siglo Xx (Tesis)." Paris: Sorbonne-Paris IV, 2011. Web. 10 agosto 2015.

Martínez Gutiérrez, Juan Tomás. "El monstruo como instrumento cognitivo y último refugio ante el mundo. Acercamiento a Bestiaria vida de Cecilia Eudave." Nada es lo que parece: estudios sobre la novela mexicana, 2000-2009. Ed. Miguel G. Rodríguez Lozano. México: UNAM, 2012. 123-144.

Nieto, Irad. "El animal sobre la piedra, de Daniela Tarazona y La ultima partida, de Gerardo Piña." Letras Libres, marzo 2009. Web. 7 agosto 2015. 
Roas, David y Ana Casas, eds. La realidad oculta. Cuentos fantásticos del siglo XX. Palencia: Menoscuarto, 2008.

Tarazona, Daniela. El animal sobre la piedra. México: Almadía, 2008.

"Los cuerpos insólitos en tres novelas de escritoras mexicanas contemporáneas." Estrategias y figuraciones de lo insólito en la narrativa mexicana (siglos XIX-XXI). Ed. Javier Ordiz. Bern: Peter Lang, 2014. 179-196.

Tentoni, Valeria. "A la orilla de la conciencia. Entrevista a Daniela Tarazona." Eterna cadencia. 15 de mayo 2015. Web. 14 septiembre 2015.

Vivero Marín, Cándida Elizabeth. "De infancias y otros monstruos difíciles. Algunos apuntes críticos." La vuelta al signo. Análisis discursivos y semióticos actuales de la literatura mexicana. Ed. Angélica Maciel y Eudave Cecilia. México: Universidad de Guadalajara, 2012. 79-87.

Volpi, Jorge. El insomnio de Bolívar: cuatro consideraciones intempestivas sobre América Latina en el siglo XXI. México: Debate, 2009.

Zamudio, Luz Elena. "Introducción. Cepa provocadora de escritoras mexicanas." Escritoras mexicanas del siglo XxI." Romance Notes 54 Special Issue (2014): 3-6. 